\title{
Almeidaia aidae Mielke \& Casagrande: seus estágios imaturos e notas taxonômicas (Lepidoptera, Saturniidae, Arsenurinae, Almeidaiini)
}

\author{
Eurides Furtado
}

Caixa Postal 97, 78400-000 Diamantino, Mato Grosso, Brasil.

\begin{abstract}
Almeidaia aidae Mielke \& Casagrande: its immature stages and taxonomical notes (Lepidoptera, Saturniidae, Arsenurinae, Almeidaiini). For the first time data on behavior, hostplants and immature stages for a member of this rare Saturniidae are presented. A female of Almeidaia aidae Mielke \& Casagrande, 1981, the fifth known specimen of this species, was collected in Diamantino, upper Arinos river, Mato Grosso, Brazil, and from its ovae, larvae were reared on Pseudobombax longiflorum (Mart. \& Zucc.) A. Rob. and Eriotheca gracilipes (K. Schum.) A. Rob. (Bombacaceae), two tree species common in the cerrado region of central Brazil. Larval development in 10 days is extraordinarily fast, however the pupal period can last a year or more. The types from Almeidaia romualdoi Travassos, 1937 and $A$. aidae are illustrated in color for the first time; of this last species, eggs, larval instars and adults are illustrated in color and the first and second larval instars and pupa, by line drawings. KEY WORDS. Bombacaceae, Brazil, Cerrado, Hostplant, Biology.
\end{abstract}

RESUMO. Dados sobre os estágios imaturos, distribuição e plantas hospedeiras para um membro desta rara espécie de Saturniidae são apresentados pela primeira vez. Uma fêmea de Almeidaia aidae Mielke \& Casagrande, 1981, o quinto exemplar conhecido desta espécie, foi coletado no alto rio Arinos, Diamantino, Mato Grosso, Brasil, e de seus ovos, larvas foram criadas com Pseudobombax longiflorum (Mart. et Zucc.) e Eriotheca gracilipes (K. Schum.) A. Rob. (Bombacaceae), duas espécies de árvores comuns na região dos cerrados do Brasil central. $O$ desenvolvimento larval em 10 dias é extraordinariamente rápido, mas o período pupal pode demorar um ano ou mais. Os holótipos de Almeidaia romualdoi Travassos, 1937 e A. aidae são ilustrados a cores pela primeira vez; desta última espécie, ovos, larvas e adultos são ilustrados a cores, e larvas de primeiro e segundo ínstares e a pupa, a traço. PALAVRAS CHAVE. Bombacaceae, Brasil, Cerrado, Plantas hospedeiras, Biologia.

Durante muitos anos Almeidaia romualdoi Travassos, 1937 (Figs 1-2) foi a única espécie do enigmático gênero criado por Travassos (1937) para o único exemplar conhecido de "um curioso lepidóptero", coletado em 1.XI.1937 na localidade de Eugênio Lefèvre, a $1.200 \mathrm{~m}$ de altitude, nas proximidades de Campos do Jordão, Estado de São Paulo. Jamais se conseguiu coletar um segundo exemplar desta espécie, embora a vegetação continua preservada em sua localidade tipo, talvez devido ao seu estranho comportamento. L. Travassos situou seu novo gênero na subfamília Ceratocampinae (mencionado pelo seu sinônimo Syssphingidae), ressaltando afinidades com Loxolonia [sic] Maassen, 1869, um Arsenurinae.

Se o adulto compartilha afinidades com estas subfamílias (Lemaire 1980, Peigler 1993), os imaturos têm características próprias, sobretudo a larva de primeiro ínstar, diferente das de todas as outras, destas duas subfamílias. Os ovos de Almeidaia assemelham-se aos de Arsenurinae, principalmente dos gêneros Loxolomia e Paradaemonia Bouvier, 1925. Entretanto esta similaridade não é um fator determinante, uma vez que em outros grupos isto se repete, como em Copiopteryx Duncan, 1841, cujo ovo e larva de primeiro ínstar, são semelhantes às de Ceratocampinae (FurTado 2001).

Em outubro de 1962, o Sr. Pedro Pompeu da Silva, um coletor do Sr. Anton Maller, este colecionador e fornecedor de insetos em Corupá, Santa Catarina, descobriu em Rio Verde, Estado do Mato Grosso do Sul, uma população de uma segunda espécie de Almeidaia, que por sua semelhança, foi confundida com A. romualdoi (Gagarin 1966, Lemaire 1980, Peigler 1993, D'Abrera 1995). Mielke \& Casagrande (1981) convencidos tratar-se de uma espécie diferente a descreveram como $A$. aidae (Figs 3-6) em homenagem à esposa do renomado lepidopterólogo Romualdo Ferreira d'Almeida, este já antes homenageado com o gênero e a espécie tipo e depois com a tribo deste fantástico Saturniidae. Todos os quatro exemplares conhecidos procedem de Rio Verde, a localidade tipo da espécie.

Os holótipos de $A$. romualdoi (Figs 1-2) e de $A$. aidae, deste também o alótipo, (Figs 3-6) são ilustrados a cores pela primeira vez. 

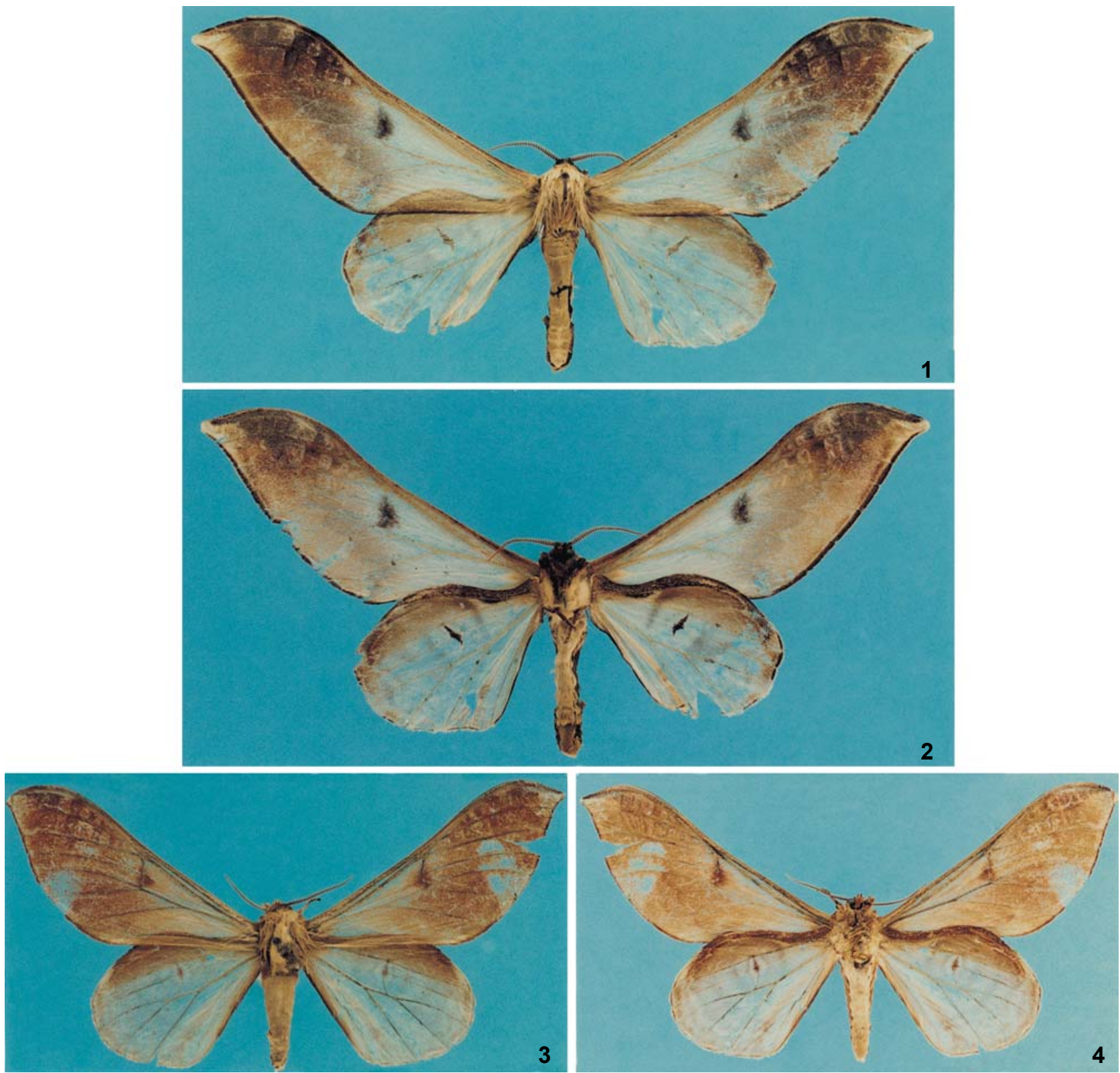

Figuras 1-4. (1-2) Almeidaia romualdoi, holótipo macho: (1) vista dorsal, (2) vista ventral, asa anterior 57,0 mm; (3-4) Almeidaia aidae, holótipo macho: (3) vista dorsal, (4) vista ventral, asa anterior 43,0 mm.

\section{MATERIAL E MÉTODOS}

A fêmea, mãe da prole que possibilitou este estudo, foi coletada em 5.IX.2000 no alto Rio Arinos, Diamantino, Mato Grosso. Nos anos seguintes, sempre nos últimos dias do mês de agosto e durante os primeiros de setembro, novos machos e fêmeas foram coletados na mesma localidade. Estes exemplares, bem como os primeiros criados em cativeiro, apresenta- ram algumas diferenças com o holótipo de A. aidae (Figs 3-4), sendo maiores e mais escuros (Figs 8-9), semelhantes ao espécimen figurado por Lemaire (1980), apenas maiores, (identificado erroneamente como A. romualdoi). Tais diferenças geraram a suspeita de tratar-se de uma espécie nova. O Dr. Olaf H. H. Mielke, após a preparação da genitália de vários machos, constatou variações entre os vários exemplares, concluindo-se ser a população do Rio Arinos (Figs 7-9) pertencente à mesma

Revista Brasileira de Zoologia 21 (3): 663-669, setembro 2004 

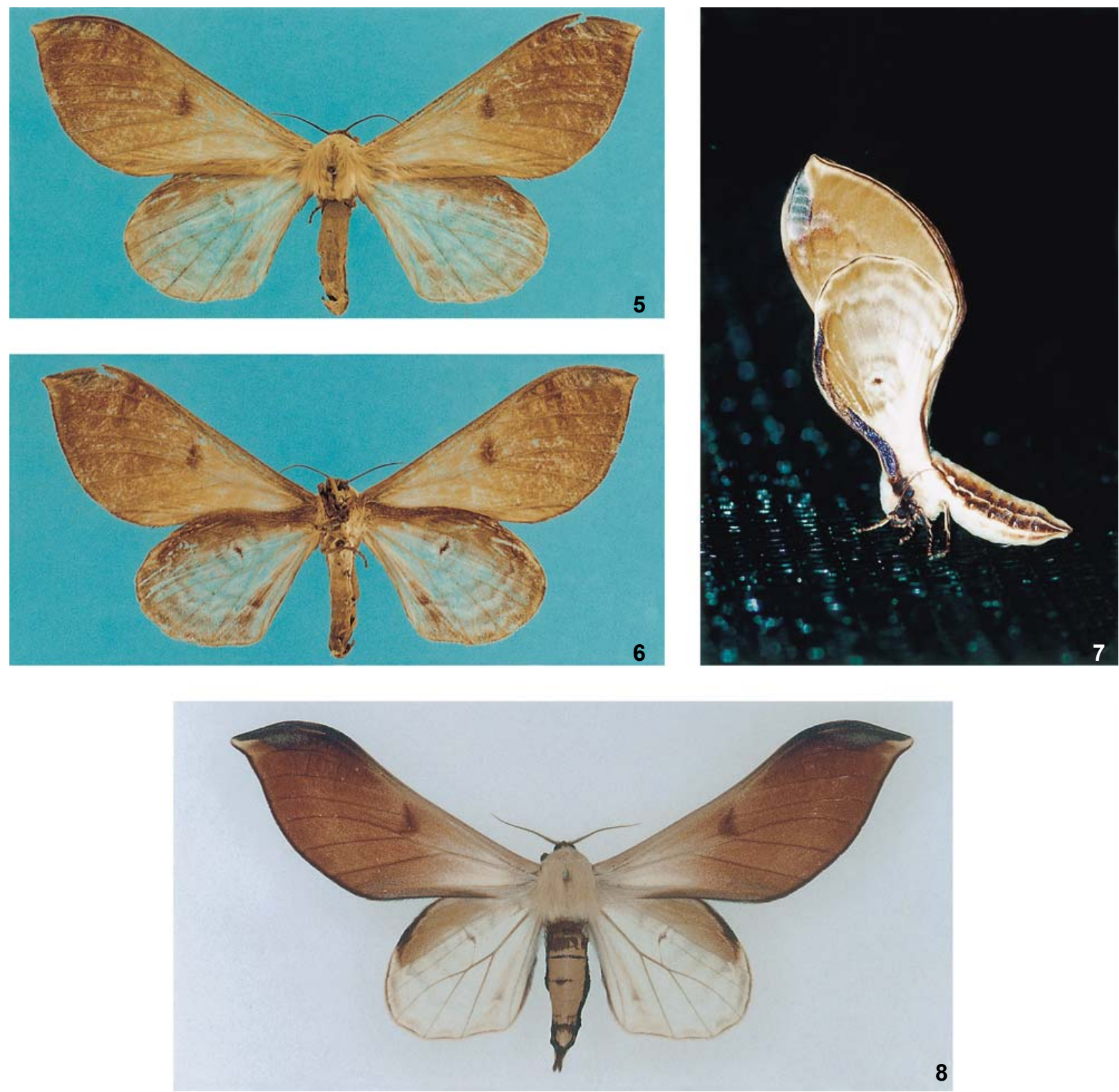

Figuras 5-8. Almeidaia aidae. (5-6) Alótipo fêmea: (5) vista dorsal, (6) vista ventral, asa anterior 47,0 mm; (7) fêmea, vista lateral; (8) macho, vista dorsal, asa anterior $53,0 \mathrm{~mm}$.

espécie encontrada em Rio Verde 41 anos atrás.

Para se chegar à planta hospedeira das larvas, estas foram divididas em cinco grupos, cada um alojado em um recipiente plástico com folhas tenras de pelo menos cinco espécies vegetais, cada uma de família diferente, e quase todas já conhecidas como hospedeiras de Arsenurinae. Dois grupos aceitaram imediatamente Pseudobombax longiflorum (Mart. et Zucc.)
A. Rob. e Eriotheca gracilipes (K. Schum.) A. Rob. (Bombacaceae), e a estes foram juntadas as sobreviventes dos demais grupos. As larvas foram mantidas nos recipientes, com limpeza e substituição diária das folhas alimentícias até o início do terceiro ínstar, quando foram transferidas para viveiros de tela plástica montados envolvendo ramagens vivas nas plantas hospedeiras e aí mantidas até o fim do estágio larval. 

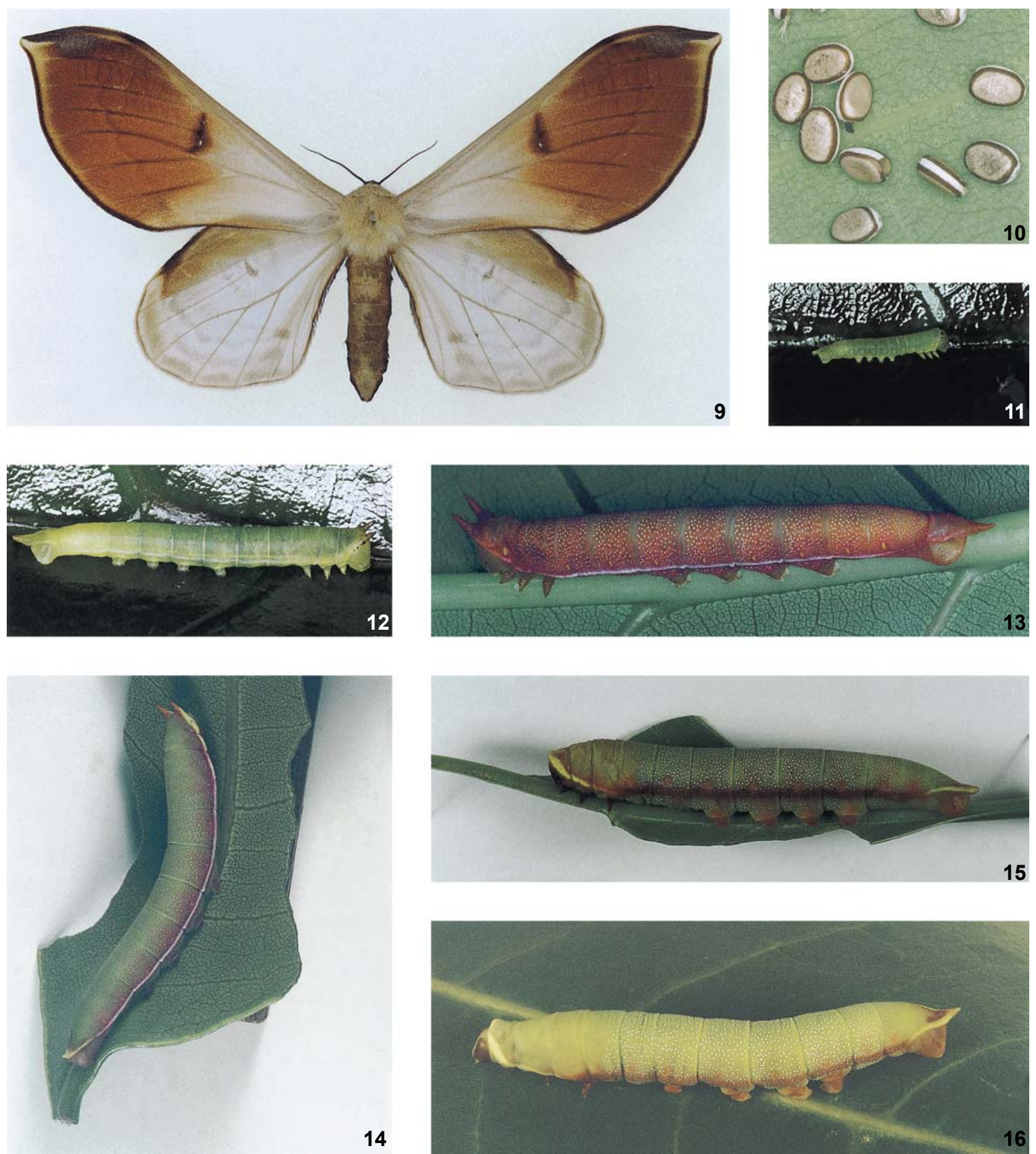

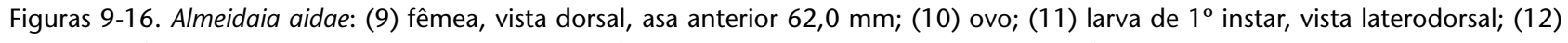
larva de $2^{\circ}$ ínstar, vista laterodorsal; (13) larva de $3^{\circ}$ ínstar, vista laterodorsal; (14) larva de $4^{\circ}$ ínstar, vista laterodorsal; (15-16) larva de $5^{\circ}$ ínstar: (15) vista lateral, (16) vista laterodorsal.

Revista Brasileira de Zoologia 21 (3): 663-669, setembro 2004 


\section{Morfologia dos imaturos Ovo (Fig. 10)}

Elipsoide, com dois lados achatados. Face maior marromclara com marmorizações pouco mais claras, orlada com coloração marrom-escura; face menor branca e com a mesma orla da face maior. Micrópila preta, num dos lados brancos. Comprimento 1,7 mm; largura 1,3 $\mathrm{mm}$; espessura 0,6 mm. Período embrionário cinco dias.

\section{Larva (Figs 11-20)}

Primeiro ínstar (Figs 11, 17-18). Cabeça arredondada, creme; frontoclípeo, mandíbulas e antenas castanho-escuras. Corpo cilíndrico com afilamento posterior. Borda anterior do pronoto franjada e com quatro verrugas pretas laterodorsais: a primeira arredondada, pequena; as duas seguintes, também arredondadas, maiores e a quarta já dorsal, ainda maior, piramidal. Tegumento liso, coloração geral creme, passando a esverdeado ou arroxeado após a primeira alimentação, de acordo com a coloração da folha onde se alimentou. Placa supranal sagital, com pequena cauda. Comprimento inicial 3,5 mm; no final do ínstar 9,5 mm. Duração um dia.

Segundo ínstar (Figs 12, 19-20). Cabeça com o mesmo formato anterior, verde-amarelada; frontoclípeo, labro, mandíbulas e antenas castanho-amareladas. Protórax com a borda anterior laterodorsalmente dilatada e com um escolo em cada lado dorsal, levemente inclinados para a frente, em forma de $\mathrm{M}$, quando vistos pela frente ou pela linha longitudinal dorsal do corpo. Placa supranal sagitiforme, terminando em pequena cauda. Coloração geral verde-clara com micro pontuação amarelada; avermelhada na faixa espiracular, da borda posterior do protórax à borda posterior de A8; castanho-escura nas áreas lateral e apical dos escolos; verde suja com fraco matiz avermelhado na placa supranal; e castanho-amarelada nas pernas torácicas. Comprimento 15,5 mm. Duração um dia.

Terceiro ínstar (Fig. 13). Semelhante ao ínstar anterior, diferindo no maior tamanho dos escolos e da placa supranal; na coloração da faixa espiracular, agora esbranquiçada, com as margens e periferia dos espiráculos avermelhados. Comprimento 25,0 $\mathrm{mm}$. Duração um dia.

Quarto ínstar (Fig. 14). Cabeça arredondada com o vértice deprimido, verde-clara suja com coloração avermelhada, exceto na fronte; antenas verde-claras com a metade apical castanho-clara. Pernas torácicas, abdominais e anais avermelhadas. Escudo supranal avermelhado, com as bordas laterais amareladas. Protórax com a ruga espiracular mais volumosa; escolos quase lisos, avermelhados e com marmorizações amareladas. Faixa espiracular esbranquiçada e com as margens avermelhadas. Tegumento verde-amarelado com granulação mais clara; marmorizações avermelhadas da faixa espiracular à área subdorsal e da mesma faixa à área subventral, nos escudos das pernas abdominais e anais e nas áreas subdorsal e dorsal do protórax; coloração amarela na ruga espiracular protorácica, da base dos escolos à borda posterior, e mesma coloração, po- rém mais fraca, na mesma ruga no mesotórax. Espiráculos elipsoidais, amarelados, peritrema pouco mais escuro. Algumas larvas têm a coloração avermelhada mais intensa, quase desaparecendo a coloração verde do tegumento. Comprimento $45,0 \mathrm{~mm}$. Duração três dias.

Quinto ínstar (Figs 15-16). Cabeça com o mesmo formato do ínstar anterior, verde-amarelada com a área laterofrontal suja com coloração avermelhada, frontoclípeo cinzento, mandíbulas pretas, antenas verde-esbranquiçadas. Corpo semelhante ao ínstar anterior, diferindo nos seguintes detalhes: ausência dos escolos protorácicos; a ruga espiracular uniformemente avermelhada da borda anterior de A1 à posterior de A8, desta cor e suja com coloração amarela em T3 e amarela da borda posterior do mesotórax à borda anterior do protórax, onde prolonga-se até a área dorsal; a granulação do tegumento mais esbranquiçada, ausente em T1-2, e apenas vestigial em T3 e A9-10; pernas abdominais e anais com coloração mais clara e translúcida. Em algumas larvas a coloração avermelhada da ruga espiracular avança laterodosalmente e ventralmente, misturando-se com o verde básico do tegumento. Comprimento $80,0 \mathrm{~mm}$. Duração quatro dias.

\section{Pupa (Figs 21-23)}

Cilíndrica com arredondamento anterior e afilamento posterior a partir de A5. Rugosidade forte no vértice, no estojo dos olhos e sua periferia, e no protórax; mesonoto, metanoto e asas nas áreas axilares e periferias com rugosidade mais suave; antenas e pernas bastante salientes, com rugosidade transversal; estojo das asas com rugosidade fina e com as veias salientes. Segmentos abdominais com rugosidade fina em A1-7 e mais grossa em A8-10. Borda posterior em A4-6 com anelação saliente, estriada longitudinalmente e com a coloração mais escura, quase preta. Espiráculos torácicos alongados e fortemente sulcados; os abdominais oblongos, também fortemente sulcados em A2-7 e quase planos em A8. Cremaster sagital, agudo, com rugosidade fina e coloração preta. Coloração geral castanho-avermelhado escura com leve brilho, mais escura, quase preta na área cefálica, nas antenas, nas pernas pro- e mesotorácicas, nos espiráculos, nas bordas posteriores de A47, na área ventral em A8-9, e em A10. Comprimento 38,0 mm; espessura 13, $0 \mathrm{~mm}$. Período pupal 339 dias.

\section{Dados bionômicos}

Pseudobombax longiflorum é uma planta típica do cerrado e a principal hospedeira de $A$. aidae. Muito raramente larvas podem ser encontradas em $E$. gracilipes, também típica do cerrado.

A postura é efetuada isoladamente ou em pequenos grupos de dois a seis ovos na maioria das vezes em reentrâncias na casca do tronco ou galhos da planta, cuja coloração é semelhante ao cório dos ovos, constituindo camuflagem eficaz. A fêmea mãe pôs 174 ovos; uma segunda fêmea, capturada dois anos mais tarde, pôs 368 ovos. A larva não se alimenta do cório; rói só o suficiente para sua saída. Após a primeira alimentação 

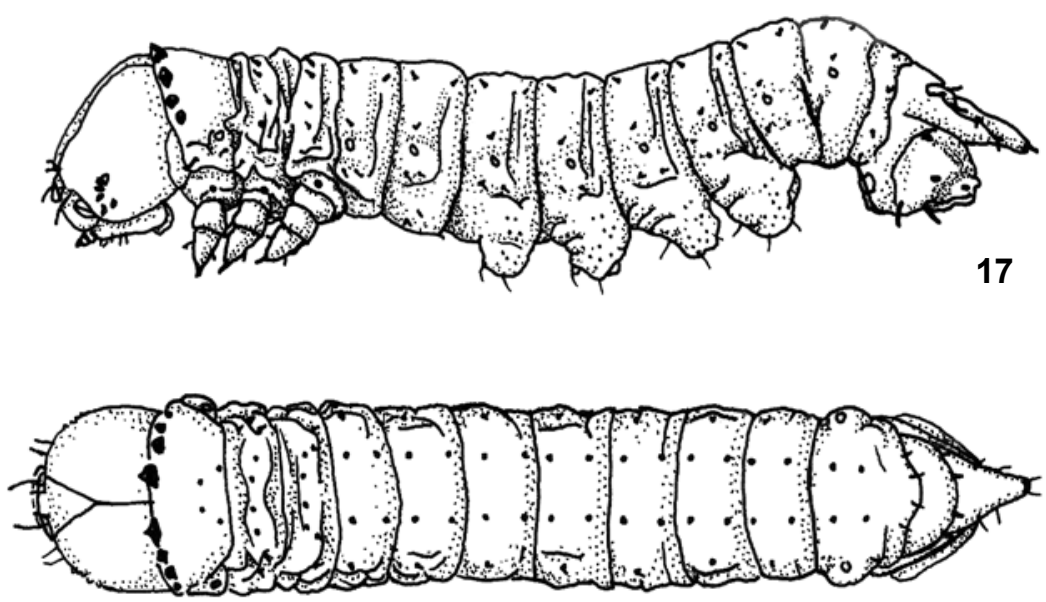

$1 \mathrm{~mm}$

18
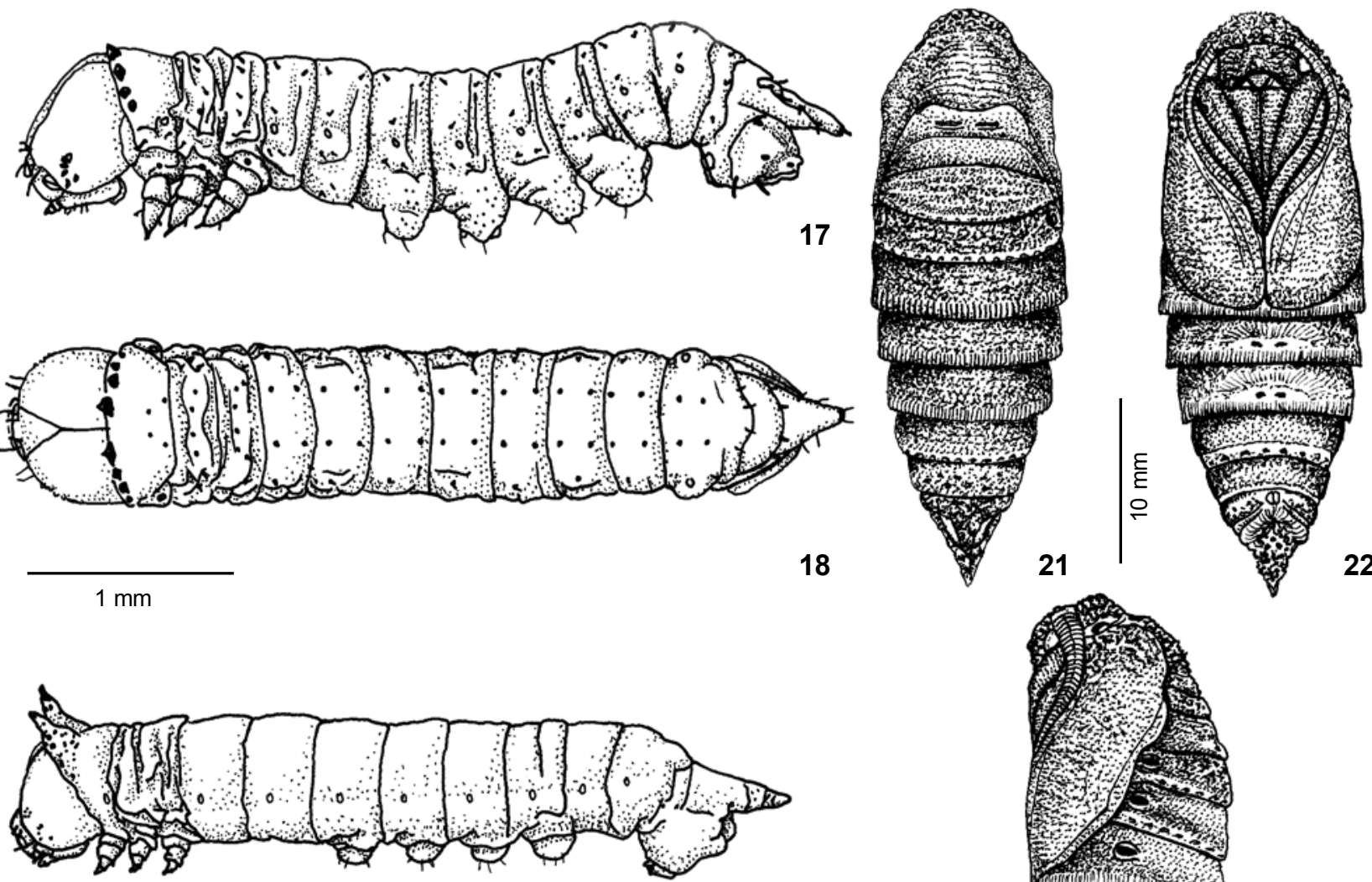

19
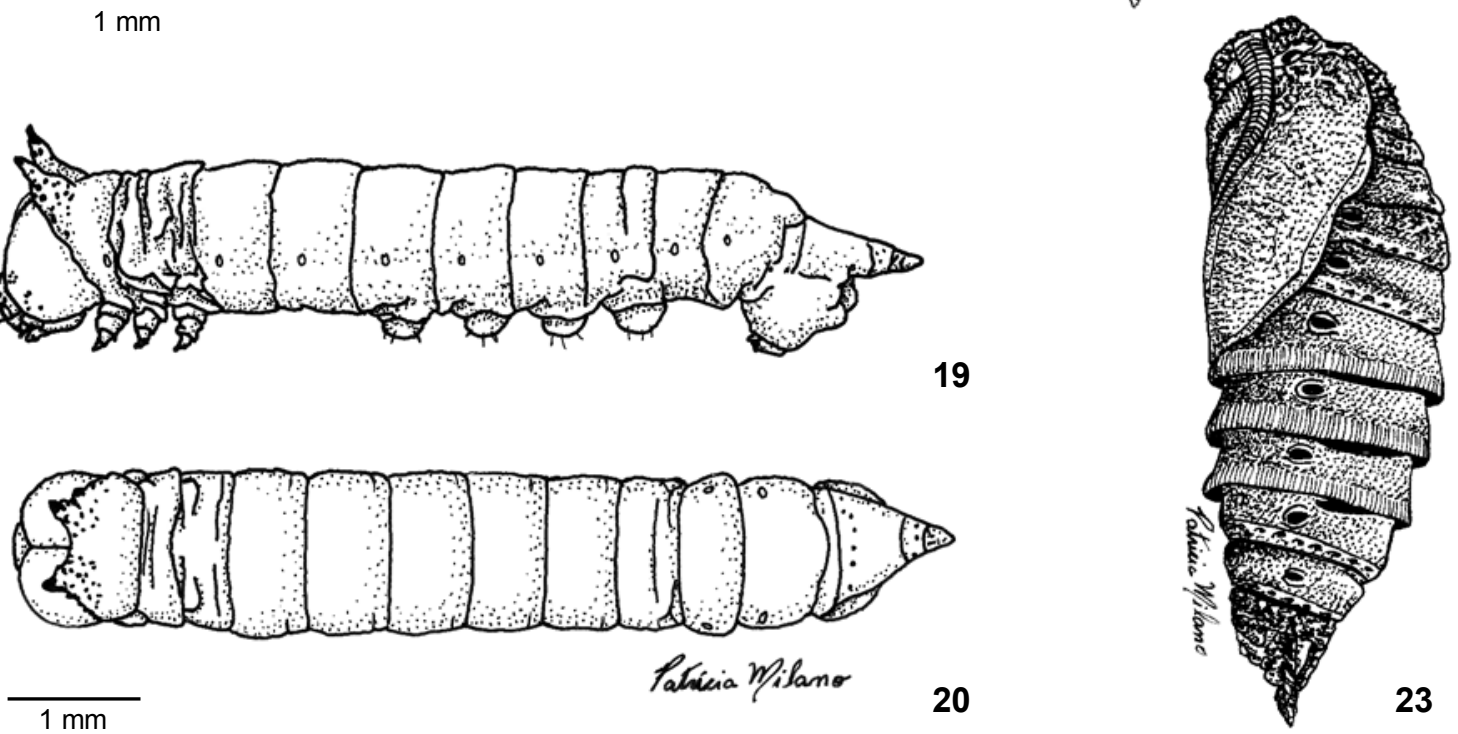

Figuras 17-23. Almeidaia aidae. (17-18) Larva de $1^{\circ}$ ínstar: (17) vista lateral, (18) vista dorsal; (19-20) larva de $2^{\circ}$ ínstar: (19) vista lateral, (20) vista dorsal; (21-23) Pupa: (21) vista dorsal, (22) vista ventral, (23) vista lateral.

assume a cor da folha alimento: verde ou arroxeada, de acordo com a brotação da planta, que muitas vezes apresenta as duas situações. Em repouso camufla-se pela coloração similar, ao pecíolo ou às nervuras da folha da planta. O baixíssimo índice de sobrevivência das larvas está relacionado ao seu diminuto tamanho na eclosão e à grande freqüência de predadores junto às folhas jovens da planta hospedeira, sobretudo vespídeos, formicídeos e reduviídeos, atraídos pelo grande número de insetos que procuram a exsudação das folhas feridas para se alimentar. No final do estágio, oculta-se no solo e dois dias depois surge a pupa.
A espécie é univoltina. O ciclo evolutivo mínimo foi de 354 dias, sendo 15 da postura à pré-pupa e 339 de período pupal. A eclosão do imago dá-se à noite entre 20:00h e 22:00h. Sua raridade em coleções deve-se ao seu curtíssimo período de vôo, não mais que duas semanas por ano, e à época não habitual de coleta, no auge da estação seca. Apesar da quase total carência de umidade, é justamente nessa época que $P$. longiflorum, usando as reservas acumuladas em volumoso caule subterrâneo, começa a vegetar depois de vários meses totalmente desfolhada.

Em repouso, o adulto mantém as asas eretas (Fig. 7), di-

Revista Brasileira de Zoologia 21 (3): 663-669, setembro 2004 
ferente das outras espécies da família, que repousam com as asas estendidas ou em forma de cumeeira. O vôo é rápido e retilíneo.

\section{AGRADECIMENTOS}

Ao amigo Dr. Olaf H.H. Mielke do Departamento de Zoologia, Universidade Federal do Paraná (UFPR) por cópias de literatura, pelas fotografias dos tipos de A. romualdoi e A. aidae, pelo exame do espécimen da coleção Claude Lemaire, no Museu Nacional de História Natural, Paris, por estudos conclusivos na identificação da espécie e por apoio e sugestões valiosas ao manuscrito; à Dra. Mirna Martins Casagrande (Departamento de Zoologia, UFPR) por ajuda valiosa nos trabalhos de identificação; ao Dr. Vitor Osmar Becker por correções e sugestões ao manuscrito; à bióloga Patrícia Milano pelos desenhos e ao Prof. Gert Hatschbach, Museu Botânico Municipal de Curitiba, pela identificação das plantas hospedeiras.

\section{REFERÊNCIAS BIBLIOGRÁFICAS}

D'Abrera, B. 1995. Saturniidae Mundi. Saturnid Moths of the
World. Keltern, Automeris Press, vol. 1, 177p.

FurTADO, E. 2001. Copiopteryx semiramis (Cramer): notas suplementares à sua biologia (Lepidoptera, Saturniidae, Arsenurinae). Revista Brasileira de Zoologia, Curitiba, 18 (2): 637 640.

GagaRIN, P. 1966. Sobre o exemplar feminino de "Almeidaia romualdoi" Travassos, 1937. Atas da Sociedade de Biologia do Rio de Janeiro, Rio de Janeiro, 10 (4): 95.

Lemaire, C. 1980. Les Attacidae Américains. The Attacidae of America ( = Saturniidae). II. Arsenurinae. Neuilly-surSeine, C. Lemaire, 199p.

Mielke, O.H.H. \& M.M. Casagrande. 1981. Notas sobre o gênero Almeidaia Travassos, com descrição de uma espécie nova (Lepidoptera, Saturniidae, Arsenurinae). Revista Brasileira de Biologia, Rio de Janeiro, 41 (4): 809-813.

Peigler, R.S. 1993. Cladisc Analysis of the Genera of the Subfamily Arsenurinae (Saturniidae). Journal of the Lepidopterists' Society, Los Angeles, 47 (3): 211-228.

Travassos, L. 1937. Sobre um novo typo de "Syssphingidae" (Lepidoptera). Rodriguesia, Rio de Janeiro, 10: 199-201.

Recebido em 12.XII.2003; aceito em 03.VIII.2004. 